\title{
Urinary symptoms, sexual intercourse and significant bacteriuria in male patients attending STD clinics
}

\author{
L M David, D Natin, $M$ Walzman, D Stocker
}

Objective: To assess the relationship between sexual behaviour, urinary symptoms, urinalysis and bacteriuria in men attending STD clinics.

Design: A prospective study recording sexual behaviour, urinary symptoms and collecting midstream urine specimens.

Setting: Two West Midlands STD clinics, UK.

Subjects: 1086 new male patients.

Results: 704 patients had had sexual intercourse (SI) within 14 days of testing, 424 had urinary symptoms and 122 had pyuria. All 13 patients with positive culture had SI < 14 days before testing, urinary symptoms and pyuria. No association was found between sexual orientation, type of SI, number of sexual partners, condom usage and bacteriuria.

Conclusion: Bacteriuria does not behave as an STD but SI may be a factor in acquiring bacteriuria. Dysuria with or without urethral discharge is the most predictive symptom of bacteriuria. Pyuria has a high sensitivity for predicting bacteriuria among males.

(Genitourin Med 1996;72:266-268)

Keywords: bacteriuria; sexual intercourse; pyuria

\section{Introduction}

In young sexually active males, clinical differentiation between urethritis, prostatitis and urinary tract infection (UTI) can be difficult. UTI, unlike urethritis, may indicate underlying urinary tract pathology and require further investigations. As the prevalence of UTI is low in young men, in most STD clinics urine culture is not a routine test. Urine cultures are requested according to clinical judgment, or abnormal reagent strip test. The association between SI and UTI in men, if there is any, lacks documentation. There are a few reported cases where male UTI was probably heterosexually acquired..$^{1-2}$ Studies comparing the prevalence of UTI between heterosexual and homosexual men gave conflicting results. ${ }^{34}$ No study has looked at the association between bacteriuria and details of sexual behaviour in both heterosexual and homosexual men. \section{Birmingham}

Whittall Street Clinic,

L M David

Genitourinary,

Medicine Department,

Coventry and

Warwickshire Hospital

D Natin

M Walzman

Genitourinary

Medicine Department

Central Out-Patients

Department, Stoke on

Trent

D Stocker

Address correspondence to:

Dr L M David, GUM

Department, Stoney Stanton

Road, Coventry CV1 4FH, UK.

Accepted for publication 16 May 1996

\section{Method}

New consecutive male patients who attended the STD clinics at Central Out-Patients Department, Stoke on Trent and Birmingham General Hospital were studied. A detailed sexual history was taken. The presence of urinary symptoms was documented. All patients had a full urogenital examination and the presence of circumcision, hypospadias or epispadias was recorded.

A midstream urine (MSU) specimen was collected from each patient. Urine cultures for significant bacteriuria were classified according to Kass's criteria as: positive $\geqslant 10,{ }^{8}$ doubt- ful $\geqslant 10^{6}-<10^{8}$, negative $<10^{6}$ pure gram positive or gram negative CFU/l. Pyuria was defined as the presence of $>10^{7} \mathrm{WB} / 1$ of unspun urine. Haematuria was defined as the presence of $>10^{7} \mathrm{RBC} / \mathrm{l}$ of unspun urine.

The Mann-Whitney test was used to compare mean age between groups. Chi square analysis of contingency tables and Fisher's exact test were used to compare frequency data between groups.

\section{Results}

Data were collected from 1168 patients; 82 who had taken antibiotics $\leqslant 3$ weeks of attendance were excluded. Of the 1086 patients studied, 337 were from Birmingham and 749 from Stoke on Trent. There were 13 positive cultures, 12 Escherischia coli and one Proteus species. Six doubtful cultures were found, five Staphylococcus epidermidis and one coliform. Mixed bacterial growth was found in 12 .
The age range was $15-80$ years: $94 \%$ were $\leqslant 45$. Mean age was 38 years in bacteriuric and 29 years in non-bacteriuric patients $(P<$ 0.02 ) (table 1). There were $60(5.5 \%)$ homosexuals (two bisexuals) and $1025(94 \cdot 4 \%)$ heterosexuals. Another patient had never had SI. The prevalence of bacteriuria was $1.7 \%$ in homosexuals and $1.2 \%$ in heterosexuals.

Last SI was < 14 days in all bacteriuric patients. In 10 it was three-seven days, in three it was nine, 10 and 13 days, but they had symptoms for three-four days. SI within the previous 14 days was the only significant difference in sexual behaviour between bacteri- 
Table 1 Epidemiological, clinical characteristics and urinalysis in bacteriuric and nonbacteriuric patients

\begin{tabular}{lllcl}
\hline & $\begin{array}{c}\text { Bacteriuric } \\
n=13(\%)\end{array}$ & $\begin{array}{l}\text { Non-bacteriuric } \\
n=1073^{*}(\%)\end{array}$ & $\begin{array}{l}\text { Total } \\
n=1086\end{array}$ & $p$ value \\
\hline Mean age (years) & 38 & 29 & 29 & $<0.02$ \\
Last SI \$ 14 days & $13(100 \%)$ & $691(64 \%)$ & 704 & $<0.006$ \\
Urinary symptoms & $13(100 \%)$ & $411(38 \%)$ & 424 & $<0.0001$ \\
$\quad$ Dysuria & 12 & 268 & 280 & $<0.0001$ \\
Diurnal frequency & 5 & 43 & 48 & $<0.0001$ \\
Nocturnal frequency & 4 & 15 & 19 & $<0.0001$ \\
Urethral discharge & 6 & 250 & 256 & \\
Miscellaneous & 6 & 80 & 56 & $<0.0001$ \\
Proteinuria & $8(64 \%)$ & $84(8 \%)$ & 92 & $<0.0001$ \\
$\geqslant 0.3$ gm/l & 3 & 19 & 22 & \\
Haematuria & $4(31 \%)$ & $33(3 \%)$ & 37 & $<0.0007$ \\
Pyuria & $13(100 \%)$ & $109(10 \%)$ & 122 & $<0.0001$ \\
\hline
\end{tabular}

$\star$ Patients with doubtful cultures (6) and contaminated cultures (12) are included.

Table 2 Sexual behaviour of bacteriuric and non-bacteriuric patients who had had sexual intercourse $\leqslant 14$ days

\begin{tabular}{lccc}
\hline & $\begin{array}{l}\text { Bacteriuric } \\
n=13\end{array}$ & $\begin{array}{l}\text { Non-bacteriuric } \\
n=691\end{array}$ & $\begin{array}{l}\text { Total } \\
n=704\end{array}$ \\
\hline Anal $^{\star}$ & $1(8 \%)$ & $35(5 \%)$ & 36 \\
Vaginal & $12(92 \%)$ & $665(96 \%)$ & 677 \\
Anal/Vaginal & $13(100 \%)$ & $691(100 \%)$ & $704 \dagger \geqslant 1$ partners \\
Anal/Vaginal & $3(23 \%)$ & $180(26 \%)$ & $183 \geqslant 2$ partners \\
Condom use: & $3(23 \%)$ & $94(14 \%)$ & 97 \\
$\quad$ persistent & $1(8 \%)$ & $25(4 \%)$ & 26 \\
not used & $9(69 \%)$ & $572(83 \%)$ & 581 \\
\hline
\end{tabular}

*Active anal intercourse.

tIncludes eight heterosexual and one bisexual who had both anal and vaginal sex.

uric and non-bacteriuric patients $(\mathrm{p}<0.006)$ Among patients whose last SI $\leqslant 14$ days, there was no significant difference between number of sexual partners, being homosexual or heterosexual, having anal or vaginal intercourse, condom use and having bacteriuria (table 2).

There were $424(39 \%)$ patients with urinary symptoms; 415 (38\%) had non-urinary symptoms only and $247(23 \%)$ were asymptomatic. Urinary symptoms were associated with and were present in all patients with bacteriuria ( $p$ $<0.0001$ ).

Among bacteriuric patients, obstructive symptoms were present in $38 \%$ of patients, irritative symptoms were present in $92 \%$ (table 1). None of the 81 patients who had urethral discharge only had bacteriuria.

There were $124(11.5 \%)$ circumcised patients and $22(2 \%)$ had hypospadias. All had negative cultures.

Urinalysis for proteinuria had $62 \%$ sensitivity and $92 \%$ specificity for detecting bacteriuria, and for haematuria had $31 \%$ sensitivity and $97 \%$ specificity. Pyuria had $100 \%$ sensitivity and $90 \%$ specificity. The positive predictive value for detecting bacteriuria was $9 \%$ for proteinuria and $11 \%$ for haematuria or pyuria.

\section{Discussion}

This is the first study to show an association between recent SI (within 14 days) and significant bacteriuria in men. A similar finding was reported in women. ${ }^{56}$ Furthermore, there was no significant difference between anal and vaginal intercourse for acquiring bacteriuria, although we acknowledge the small number of patients who had anal intercourse in the study. We found in men, as others found in women,? that promiscuity or condom use are not fac- tors, unlike STDs, in acquiring bacteriuria. To explain these findings, we postulate that SI facilitates ascending infection from the distal urethra.

No asymptomatic bacteriuria was found. Unlike women, asymptomatic bacteriuria in men is confined to the elderly. ${ }^{8}$ The prevalence of bacteriuria was low, $1.2 \%$ in our clinics and $1.5 \%$ in another STD clinic. ${ }^{4}$ Neither study looked for fastidious or anaerobic bacteria or fungi. Both defined bacteriuria as the presence of $\geqslant 10^{8} \mathrm{CFU} / \mathrm{l}$. Contamination of voided urine with genitoperineal flora is less likely in men than women. In men, growth of $\geqslant 10^{6} \mathrm{CFU} / 1$ in MSU was found to have $97 \%$ sensitivity and $100 \%$ specificity in detecting significant bacteriuria. ${ }^{9}$

Although $32 \%$ of patients had symptoms which were suggestive of a UTI (when only one urine specimen was cultured for aerobic pathogens alone), only $3 \%$ of patients with urinary symptoms had positive cultures. Bacteriuria was $4 \%$ among patients with irritative symptoms and $10 \%$ with obstructive symptoms. Dysuria, irrespective of urethral discharge, was the most predictive symptom of bacteriuria, but was present in $26 \%$.

Five of the six patients with bacteriuria and urethral discharge were diagnosed as having non-gonococcal non-chlamydial urethritis. This supports the suggestion in other studies $^{310}$ that patients with urethral discharge may have urethritis due to $E$ coli or other urinary pathogens. It illustrates that urethritis and UTI cannot be distinguished on clinical grounds and/or urethral smears.

We found urinalysis for proteinuria or haematuria had low sensitivity for detecting bacteriuria. Testing for both had $69 \%$ sensitivity. Studies using leukocyte esterase or nitrite dipsticks found their sensitivity in predicting bacteriuria was $<70 \%$ which was not superior to pyuria. ${ }^{11}$

Our findings, as others, ${ }^{12}$ showed that using quantitative urinalysis, bacteriuria is regularly associated with presence of $\geqslant 10^{7} \mathrm{WBC} / 1$ unspun urine. The finding of pyuria is consistent with, but not diagnostic of, bacteriuria. A negative culture in symptomatic patients with pyuria is an indication to repeat urine culture including culture for fastidious bacteria. Persistent sterile pyuria may require investigation for other causes including prostatitis, urolithiasis, genitourinary malignancy or tuberculosis. A semiquantitative leucocyte count to detect pyuria can be done using microscopy. ${ }^{812}$

As an on-site laboratory is available in most STD clinics, urinalysis to detect pyuria as a screening test for bacteriuria is advisable. It provides a sensitive, rapid, inexpensive screening test for bacteriuria. It will explain the cause of urethritis in some patients and detect sterile pyuria in others.

1 Wong ES, Stamm WE. Sexual acquisition of urinary tract infection in a man. $\mathcal{F} A M A 1983 ; 250: 3087-8$.

2 Simpson B. Marital urinary infection. $B M \mathcal{F} 1976 ; 2: 520$.

3 Barnes RC, Diafuku R, Roddy RE, Stamm WE. Urinarytract infection in sexually active homosexual men. Lancet $1986 ; 1: 171-3$. 
4 Wilson AP, Tovey SJ, Adler MW, Gruneberg RN Prevalence of urinary tract infection in homosexual and heterosexual men. Genitourin Med 1986;62:189-90.

5 Nicolle LE, Harding KM. The association of urinary tract infection with sexual intercourse. $F$ Infect Dis 1982;146: 579-83.

6 Buckley RM, McGuckin M, MacGregor RR. Urine bacterial counts after sexual intercourse. N Engl $¥$ Med 1978; 298:321-4.

7 Gillespie WA, Sellin MA, Gill P, Tuckwell LA, Hilton AL Urinary tract infections in young women with special reference to staphylococcus saprophyticus. $f$ Clin Pathol 1978;31:348-50.

8 Norman DC, Yamamura R, Yoshikaawa TT. Pyuria: its predictive value of asymptomatic bacteriuria in ambula- tory elderly men. $\mathcal{f}$ Urol $1986 ; 135: 520-2$.

Lipsky BA, Ireton RC, Fihn SD, Hackett R, Berger RE Diagnosis of bacteriuria in men: specimen collection and culture interpretation. $\mathcal{F}$ Infect Dis 1987;155:847-53.

10 Lipsky BA. Urinary tract infection in men: epidemiology, pathophysiology, diagnosis, and treatment. Ann Intern Med 1989;110:138-50.

11 Hoberman A, Wald ER, Renolds EA, Penchansky L, Charron $M$. Pyuria and bacteriuria in urine specimen obtained by catheter from young children with fever. $\mathscr{F}$ Pediatr 1994;124:513-9.

12 Musher DM, Thorsteinsson SB, Airola II VM. Quantitative urinalysis diagnosing urinary tract infection in men. $\mathfrak{f} A M A$ 1976;23:2069-72. 